
У БОЛЬНЫХ С ТЯЖЕЛОЙ ЧЕРЕПНО-МОЗГОВОЙ ТРАВМОЙ

\author{
С. Ю. Козлов, Н. В. Шаповалова
}

\author{
Воронежская областная клиническая больница № 1, \\ Воронежская государственная медицинская академия им. Н. Н. Бурденко
}

\title{
Correction of Systemic Hemodynamics and Gas Exchange in Patients with Severe Brain Injury
}

\author{
S. Yu. Kozlov, N. V. Shapovalova
}

Voronezh Regional Clinical Hospital One, N. N. Burdenko Voronezh State Medical Academy, Ministry of Health and Social Development of the Russian Federation

\begin{abstract}
Интенсивная терапия больных с тяжелой черепно-мозговой травмой должна проводиться с учетом повреждающих факторов. Адекватность коррекции системной гемодинамики и кислородного обеспечения в остром периоде тЧМТ определяет эффективность проводимого лечения. Обследовано и проведено лечение 67 больных, перенесших тЧМТ (в возрасте от 21 до 68 лет) - 28 пациентов по стандартной базовой схеме, 39 пациентов - лечение с позиций направленной коррекции повреждающих факторов. Проводили комплексную оценку больных. Исходы оценивали с использованием шкалы исходов Глазго. Эпизоды гипоксии и артериальной гипотензии были обнаружены у практически равного количества пострадавших обеих групп - до 90\%. Больным второй группы исключали даже короткие периоды гипотонии. Поддерживалось среднее артериальное давление выше 90 мм рт. ст., своевременно восполнялся ОЦК. При угнетении сознания (менее 9 баллов по ШКГ) если сохранялась гипоксия, производилась эндотрахеальная интубация, что позволяло осуществить управляемую ИВЛ. С целью коррекции внутренней среды использовались аминокислотные препараты, жировые эмульсии, препараты гидроксиэтилкрахмала, сбалансированные энтеральные смеси. Направленная коррекция повреждающих факторов в группе II позволила снизить число неблагоприятных исходов и летальность.

Intensive care of patients with severe brain injury (SBI) should be performed, by taking into account damaging factors. The adequacy of correction of systemic hemodynamics and oxygen support in acute SBI determines the effectiveness of the performed treatment. Sixty-seven patients aged 21 to 68 years who had experienced SBI were examined and treated (28 patients were treated with the routine basic regimen and 39 were treated via goal-oriented correction of damaging factors). A comprehensive examination of the patients was made. The outcomes of therapy were assessed, by using the Glasgow coma scale (GCS). The episodes of hypoxia and arterial hypotension were detected in the virtually equal number of victims (as high as $90 \%$ ) in both groups. The outcomes of therapy were better in patients without arterial hypotension. The mean blood pressure was maintained at a level of higher than $90 \mathrm{~mm}$ $\mathrm{Hg}$; the volume of circulating blood was replenished. Endotracheal intubation was made in patients with depressed consciousness (less than 9 scores by GCS) if hypoxia was retained, which permitted controlled artificial ventilation to be performed. Amino acid drugs, fatty emulsions, hydroexyethyl starch preparations, and balanced enteral formulas were used to correct the internal environment. Goal-oriented correction of damaging factors in Group 2 reduced the number of poor outcomes and death rates.
\end{abstract}

Интенсивная терапия (ИТ) больных с тяжелой черепно-мозговой травмой (ТЧМТ) должна проводиться с учетом процессов, происходящих в организме больного. Большинство авторов считают, что раннее выявление и устранение повреждающих факторов - основная цель в лечении пострадавших с ТЧМТ [1-4]. Вторичные повреждения мозга, развивающиеся при воздействии внутри- и внечерепных факторов, рассматриваются как потенциально обратимые. Современные диагностические возможности и методы ИТ позволяют существенно снизить летальность больных с ТЧМТ, однако исходы заболевания не всегда благоприятны, остается много пациентов с выраженной инвалидизацией $[1,2]$.
Известно, что эпизоды артериальной гипотензии у больных с ТЧМТ (систолическое АД менее 90 мм рт. ст.) и артериальной гипоксемии ( $\mathrm{PaO} 2$ менее 60 мм рт. ст.) как в ближайшие часы, так и в ближайшие сутки и даже недели после травмы являются прогностически неблагоприятными признаками. Особенно они опасны у больных с внутричерепной гипертензией $[2,3$, $5,6]$.

В связи с этим адекватность коррекции системной гемодинамики и кислородного обеспечения в остром периоде ТЧМТ во многом определяет эффективность проводимой ИТ.

Цель работы - направленная коррекция системной гемодинамики и кислородного режима на этапах лечения пострадавших с ТЧМТ. 


\section{Материал и методы исследования}

Обследовано и пролечено 67 больных, перенесших ТЧМТ (в возрасте от 21 года до 68 лет). Согласно проводимому лечению больные были разделены на 2 группы. 1-я группа включала 28 пациентов, получавших стандартное базовое лечение с момента поступления в стационар, требуемое для нейрохирургических больных в критических состояниях, а 2-я - 39 пациентов, получавших лечение согласно протоколу с позиций направленной коррекции повреждающих факторов.

Проводили комплексную оценку состояния с момента поступления в стационар: 1) исследование церебральных функций по данным КТ, МРТ, неврологическому статусу; 2) мониторинг жизненно важных функций (с помощью системы прикроватных мониторов) и внутреннего гомеостаза (методом биохимической экспресс-диагностики). Исходы оценивали с использованием шкалы комы Глазго (ШКГ)

Как на этапе первоочередных лечебно-диагностических мероприятий, так и в ходе плановой ИТ предпочтение отдавали мониторному (непрерывному) слежению за гемодинамическими параметрами. АД измеряли неинвазивным способом (с помощью определения тонов по Короткову) с использованием прикроватного монитора [3, 7].

Мониторинг внешнего дыхания и газообмена исследовали с использованием пульсоксиметра, системы прикроватного мониторинга, исследовали частоту, глубину и ритм дыхания, адекватность, патологические типы дыхания.

Статистическую обработку данных проводили в операционной среде Windows.

\section{Результаты исследований и обсуждение}

Наиболее часто встречаемые эпизоды гипоксии и артериальной гипотензии были обнаружены у практически равного количества пострадавших обеих групп - до $90 \%$.

При ведении больных 2-й группы с ТЧМТ особое внимание уделялось поддержанию нормального уровня АД и исключению даже коротких периодов гипотонии. Поддерживалось среднее АД выше 90 мм рт. ст. Восполнение объема циркулирующей крови (ОЦК) проводили вначале переливанием до 2 л сбалансированных солевых растворов (Рингер лактат или физиологический раствор) под мониторным контролем АД и уровня волемии. Гиповолемия быстро корригировалась инфузией коллоидов, кристаллоидов и препаратов крови. При устойчивой артериальной гипотензии использовались коллоидные растворы (декстраны, 5\% раствор альбумина) для восполнения внутрисосудистого объема жидкости и преднагрузки. Вазопрессоры и инотропные препараты вводили только на фоне нормоволемического состояния для поддержания АД и адекватной церебральной перфузии (адреналин, норадреналин, допамин).

Важно было установить и исключить экстракраниальный источник кровотечения, особенно при сочетанной ЧМТ. Гемотрансфузия проводилась при кровопотере, оцениваемой не менее чем 20-30\% ОЦК. Всем больным с угнетением сознания (менее 9 баллов по ШКГ), если сохранялась гипоксия, несмотря на оксигенотерапию, производилась эндотрахеальная интубация, что позволяло осуществить управляемую ИВЛ для поддержания адекватной оксигенации, предотвращения аспирации и снижения метаболизма за счет исключения возможной моторной гиперреактивности. При сочетании ЧМТ с челюстно-лицевой травмой, а также при признаках обструкции верхних дыхательных путей вследствие прямой травмы гортани выполнялась ранняя трахеостомия.

Основой энергетического обеспечения больных 1-й группы оставалась глюкоза в различных концентрациях (5-30\% растворы). Восстановление белкового состава проводилось вливанием свежезамороженной плазмы. Как интраоперационно, так и в послеоперационном периоде плазмозамещающие растворы были представлены в подавляющем большинстве декстранами. 2-я группа отличалась увеличением использования аминокислотных препаратов с полным набором аминокислот и энергообеспечения за счет жировых эмульсий МСТ/ЛСТ 50/50, с отчетливой тенденцией к уменьшению или отказу от плазмы крови и расширением использования препаратов гидроксиэтилкрахмала, сбалансированных энтеральных смесей.

В результате направленной коррекции повреждающих факторов во 2-й группе значимого влияния эпизодов артериальной гипотензии и гипоксии выявлено не было. В этой же группе отмечалось снижение числа неблагоприятных исходов и летальности.

\section{Заключение}

Следует тщательно избегать или немедленно устранять артериальную гипотензию (систолическое АД < 90 мм рт. ст.). Среднее АД следует поддерживать выше 90 мм рт. ст. путем инфузии жидкостей, чтобы сохранять церебральное перфузионное давление не ниже 70 мм рт. ст. Артериальная гипотония (систолическое АД $<90$ мм рт. ст.), особенно в сочетании с гипоксией, являются прогностически неблагоприятными факторами. ИТ больных с ТЧМТ должна проводиться под непрерывным контролем с позиций возможно раннего выявления и своевременного устранения факторов вторичного повреждения головного мозга. Применение современного диагностического и лечебного потенциала способствует снижению летальности больных с ТЧМТ и возрастанию числа благоприятных исходов. 


\section{Литература}

1. Гайтур Э. И., Потапов А. А., Амчеславский В. Г., и др. Значение артериальной гипотонии и гипоксии на догоспитальном периоде для исходов тяжелой сочетанной и изолированной черепно-мозговой травмы. В кн.: Актуальные проблемы нейрохирургии. Сыктывкар; 1996: $24-25$.

2. Коновалов А. Н. и соавт. Клиническое руководство по черепно-мозговой травме. Т 2. М: Антидор; 1999: 158-210.

3. Царенко С. В. Интенсивная терапия нарушений гемодинамики и дыхания при черепно-мозговой травме. Нейрохирургия. 1998; 2: 4-8.

4. Chesnut R. M., Marshall S. B., Piek J, et al. Early and late systemic hypotension as a frequent and fundamental source of cerebral ischemia following severe brain injury in the Traumatic Coma Data Bank. Acta Neurochir. 1993; 59 (Suppl): 121-125.
5. CruzJ. An additional therapeutic effect of adequate hyperventilation in severe acute brain trauma, normalization of cerebral glucose uptake. J. Neurosurg. 1995; 82: 379-385.

6. Miller J. D. et al. Further experience in the management of severe head injury. J. Neurosurg. 1981; 54: 289-299.

7. Cockings J. G. L., Webb R. K., Klepper I. D. et al. Blood pressure monitoring-applications and limitations, an analysis of 2000 incident reports. Anest. Intens Care. 1993; 21: 565-569.

\section{ИНФОРМАЦИЯ \\ о проведении секции «Экстремальные состояния. Постреанимационная патология» в рамках Третьего Российского Конгресса по патофизиологии (9-11 ноября 2004 г.)
Information on the Section «Emergencies. Postresuscitation Pathology» Held within the Framework of the Third Russian Congress on Pathophysiology (November 9-11, 2004)

11 ноября 2004 г. в рамках III Российского Конгресса по патофизиологии состоялась секция «Экстремальные состояния. Постреанимационная патология», которая состояла из двух заседаний: первое - «Критические состояния и перспективные реаниматологические технологии» и второе заседание - «Кровопотеря, шок, постреанимационная болезнь. Патогенез, принципы лечения», на которых присутствовало около 100 человек.

Открыл заседание секции Председатель, член-корреспондент РАМН, профессор В. В. Мороз. На первом заседании было заслушано десять докладов. Первый доклад «Саногенетический подход к оценке индивидуального риска в условиях воздействия антропогенных факторов» прочитал Карганов М. Ю. (Москва).

Доклад Ройтмана Е. В. (РНЦХ, Москва) «Признаки гепарин-индуцированной тромбоцитопении у больных после операций с искусственным кровообращением» вызвал много вопросов и дискуссию

Участники секции проявили особый интерес к докладу профессора Ляско Л. И. (г. Обнинск) «Дизрегуляционные нарушения адаптационно-защитных систем и их коррекция у ликвидаторов последствий аварии на Чернобыльской АЭС», в котором отражены результаты совместных исследований российских и японских ученых, занимающихся проблемами радиационного облучения.

Шуливейстров Ю. А. из Новокузнецка представил доклад «Роль железосвязывающих белков острой фазы при тяжелой черепно-мозговой травме».

Группа докладов была представлена сотрудниками НИИ общей реаниматологии РАМН: профессор Молчанова Л. В. доложила о «Дислипопротеидемии у больных в критических состояниях»; Мещеряков Г. Н. - «Острое повреждение легких: биохимические маркеры»; Власенко А. В. - «Выбор параметров ИВЛ у больных с острым респираторным дистресс-синдромом».

Два доклада были представлены учеными Омской государственной медицинской академии. Русаков В. В. «Сократимость миокарда крыс после черепно-мозговой травмы» и профессор Долгих В. Т. - «Использование рефортанта для коррекции гиповолемии у новорожденных».

Шевантаева О. Н. из Нижнего Новгорода представила доклад «Механизмы нарушения сперматогенеза в постреанимационном периоде».
На втором заседании секции «Кровопотеря, шок, постреанимационная болезнь. Патогенез, принципы лечения» было заслушано десять докладов.

Интерес вызвал доклад профессора Е. Monos из Венгрии, который прозвучал на английском языке. Была дискуссия по изложенной теме.

Молодыми учеными были представлены интересные экспериментальные доклады. Это доклад Жуковой А. Г. с соавторами - «Резистентность мембранных структур мозга, сердца и печени после реанимации при системной остановке кровообращения у пассивных и активных животных»; доклад Алексеевой П. Ю. с соавторами - «Эффективность дефибриллирующих импульсов в модельном эксперименте» и доклад Бугровой М. Л. с соавторами из Нижегородской медакадемии - «Морффункциональные изменения регуляторных систем в реперфузионном периоде».

Лескова Г. Ф. выступила с докладом «Механизмы клеточных повреждений органов-мишеней при геморрагическом шоке и защитный эффект липосом».

Доклад патофизиологов из Воронежской медакадемии «Гипербарический кислород как модулятор адаптации функциональных систем при гипоксии» представил Тумановский Ю. М.

Четыре доклада были представлены патофизиологами из НИИ общей реаниматологии РАМН: доклад профессора Кожуры В. Л. с соавторами - «Состояние холинергической медиаторной системы головного мозга в раннем постреанимационном периоде после массивной кровопотери», доклад профессора Голубева А. М. с соавторами - «Метаболические нарушения в нейронах ЦНС при массивной кровопотере и их коррекция перфтораном», доклад профессора Волкова А. В. с соавторами - «Постреанимационный нейропротекторный эффект репродуктивных гормонов», доклад Заржецкого Ю. В. с соавторами - «Механизм дизрегуляции ориентировочноисследовательского поведения у крыс в постреанимационном периоде».

Дискуссии, которые с интересом прошли по каждому из докладов, не оставили равнодушных.

Подвели итоги заседаний секций председатели: членкорреспондент РАМН, профессор В. В. Мороз, профессор В. Т. Долгих, Г. Н. Мещеряков. 